\title{
The interaction of contextual and syntactic information in the processing of Turkish anaphors"
}

\author{
Martina Gračanin-Yuksek ${ }^{1}$, Sol Lago ${ }^{2}$, Duygu Fatma Şafak ${ }^{3}$, Orhan Demir ${ }^{1} \&$ Bilal \\ Kirkic1 ${ }^{1}$ \\ ${ }^{1}$ Department of Foreign Language Education, Middle East Technical University, Ankara, Turkey \\ ${ }^{2}$ Potsdam Research Institute for Multilingualism, Potsdam, Germany \\ ${ }^{3}$ Technische Universität Braunschweig, Braunschweig, Germany
}

Corresponding author: Martina Gračanin-Yuksek

martina@metu.edu.tr

Middle East Technical University

Department of Foreign Language Education

06531 Ankara, Turkey

Tel: +90 (312) 2107530

Fax: +90 (312) 2107969

\footnotetext{
*This work was sponsored by the Alexander-von-Humboldt foundation and by grant $113 \mathrm{~K} 458$ awarded by TÜBITAK, the Scientific and Technological Research Council of Turkey.
} 


\begin{abstract}
In contrast with languages where anaphors can be classified into pronouns and reflexives, Turkish has a tripartite system that consists of the anaphors $o$, kendi, and kendisi. The syntactic literature on these anaphors has proposed that whereas $o$ behaves like a pronoun and kendi behaves like a reflexive, kendisi has a more flexible behavior and it can function as both a pronoun and a reflexive. Using acceptability judgments and a self-paced reading task, we examined how Turkish anaphors are processed in isolated sentences and within larger discourse contexts. We manipulated contextual information by creating passages where the context favored a local, long-distance or extra-sentential referent prior to the appearance of the anaphor. We measured the effect of the context on participants' reading times and their end-of-trial coreference assignments. Our results suggest that contextual information affects the interpretive possibilities associated with an anaphor, but that the influence of context depends on the degree to which the anaphor is syntactically constrained.
\end{abstract}

Keywords: coreference, Turkish, syntactic constraints, discourse, sentence processing. 


\section{Introduction}

Studies of anaphora seek to understand the mental computations used to identify the referent of an anaphor. As referent identification involves the use of lexical, grammatical and contextual knowledge, an open question is how these kinds of information interact during processing, such that speakers can combine them in a quick and effortless manner. This paper focuses on the interaction between syntactic and contextual information by examining how prior context affects coreference when the antecedent favored by the context is syntactically accessible or inaccessible to an anaphor.

Research on syntactic processing has shown that anaphor interpretation is influenced by the constraints proposed in Binding Theory (Chomsky 1981). For example, the set of possible antecedents of a reflexive like himself seems to be initially limited to syntactically accessible antecedents, i.e., those that c-command the reflexive and are within its local domain, as proposed by Principle A of the Binding Theory (Nicol and Swinney 1989; Sturt 2003; Xiang et al. 2009; Felser and Cunnings 2012). Related research has been conducted on pronouns like him and her, which are subject to a syntactic constraint known as Principle B: a pronoun cannot be bound by an antecedent within its local clause. Most of these studies have shown that syntactically accessible elements are preferentially considered as antecedents for a pronoun, although studies differ in whether they find syntactically unlicensed elements to be considered as well (Clifton et al. 1997, 1999; Badecker and Straub 2002; Kennison 2003; Runner et al. 2006; Lee and Williams 2008; Patterson et al. 2014; Chow et al. 2014; for review see Sturt, 2013).

Meanwhile, a different line of work has shown that information other than syntactic constraints also plays a role in anaphor interpretation. This information includes general world knowledge and the semantic and pragmatic configuration of the discourse preceding the anaphor, which may make some antecedents more plausible than others. For example, first-mentioned antecedents are more likely to be referents than those mentioned later (Gernsbacher and Hargreaves 1988; Gernsbacher et al. 1989; Cheng et al. 2000). Further, the choice of an antecedent in causal and result clauses is influenced by the connective introducing the clause and by the semantic properties of the verb in the matrix clause (Koorneef and van Berkum 2006; Featherstone and Sturt 2010; Pyykkönen and Järvikivi 2010; Cozijn et al. 2011).

In short, anaphor interpretation is influenced both by syntactic constraints and by the information provided by the discourse context. This raises the question of how speakers integrate these two types of information during comprehension. Several studies have addressed this question. For example, Felser and Cunnings (2012) and Patterson et al. (2014) found that reflexive and non-reflexive anaphor resolution in native, but not in nonnative speakers of English, is, at least in the early stages of processing, guided by structural principles of the binding theory and is not affected by non-structural considerations, such as saliency and discourse-prominence of the antecedent. However, fewer studies have examined anaphor resolution in sentences preceded by a context that clearly favored a particular referent as the antecedent of the anaphor. Gordon and Scearce (1995) examined how contextual information affects a previously reported structural preference to interpret a pronoun as coreferential with an antecedent that carries the same grammatical role: pronouns in subject position prefer antecedents that are also in subject position, whereas 
pronouns in object position prefer antecedents that are in object position (Maratsos 1973; Sheldon 1974; Stevenson et al. 1995; Streb et al. 1999).

In two self-paced reading experiments, Gordon and Scearce replicated the structural preference for subject pronouns to refer to subject antecedents and they further examined how this preference interacted with the position of the information disambiguating the referent of the pronoun, which could either precede or follow it. In their first experiment, where the disambiguating information followed a subject pronoun, they found that participants experienced processing difficulty when the disambiguating information resolved the pronoun towards the object, rather than the subject antecedent. In their second experiment, the disambiguating information was placed before the pronoun to test whether the early availability of context would block the structural preference towards a subject antecedent. In this experiment participants also showed processing difficulty when the disambiguating context favored an object antecedent, but this effect was reduced compared to the first experiment, suggesting that contextual information interacted with the structural bias despite not being able to override it.

In a similar vein, Li and Kaiser (2009) addressed the interaction of contextual and structural factors in the interpretation of the Chinese reflexive $z i j i$ 'self', which can refer to both local and long-distance antecedents. The authors conducted an offline survey and a self-paced reading task. In the offline survey, they compared the interpretation of ziji when preceded by a neutral context and when the preceding context biased its interpretation towards a long-distance antecedent. In neutral contexts, participants mostly chose the local subject as the antecedent of ziji. However, in contexts favoring the long-distance antecedent, preferences were reversed, with participants mainly choosing the long-distance antecedent, which was consistent with the context. This result indicates that the contextual information was able to override the local bias obtained in neutral contexts. In a further self-paced reading experiment, Li and Kaiser showed that the bias of the context affected participants' reading times from early on, at the reflexive itself.

Taken together, these studies show that comprehenders use both structural and contextual information to process anaphors in real time. Our study builds on these findings and investigates the interaction between structural constraints and a biasing context in the processing of Turkish anaphors. However, we ask not only how an anaphor is interpreted following a context that favors one of several syntactically legitimate antecedents, but also how it is interpreted when the context favors an antecedent that is syntactically inaccessible according to the principles of the Binding Theory.

We consider three possible ways in which syntactic and contextual information may combine in such configurations. One alternative is that the syntactic constraints of an anaphor fully determine its interpretation. In this case, speakers should assign an antecedent to an anaphor only when the antecedent is licensed by the principles of the Binding Theory, regardless of the context. A second possibility is for contextual information to play a dominant role in determining the interpretation of an anaphor. In this case, we expect speakers to always resolve anaphors to the antecedent supported by contextual information, regardless of the syntactic constraint of the anaphor. Finally, syntactic and contextual information might interact in a more nuanced way. For instance, the effect of the context might depend on the degree to which the anaphor is constrained by syntax. 
Our study allows us to explore this third possibility because the anaphoric system of Turkish differs from languages like English in an interesting way. Turkish has a tripartite anaphoric system with anaphors that are differentially constrained by syntactic information, such that two of these anaphors are syntactically constrained in the choice of an antecedent, but one is not. The fact that Turkish anaphors are syntactically constrained to different degrees is useful to examine the relative contribution of syntactic and contextual information to anaphor interpretation. Before we describe the design of our study, we outline the behavior of Turkish anaphors in the constructions used in our study.

\section{The anaphoric system of Turkish}

The present study examined three anaphors, kendi, o, and kendisi, in configurations where they appeared as direct objects of a verb in an embedded clause. The Turkish reflexive kendi 'self', is generally considered to be subject to Principle A of the Binding Theory. Most accounts posit that kendi needs to be bound by a local c-commanding antecedent (Underhill 1976; George and Kornfilt 1981; Enç 1989; Kornfilt 2001; Göksel and Kerslake 2005; Rudnev 2008; Meral 2010, 2013). This constraint is shown in (1), which is taken from our experimental materials. We use the index $k$ to refer to an extrasentential antecedent, which is absent from the sentence. Notice that in contrast with English, Turkish anaphors are not gender marked because Turkish lacks grammatical and natural gender.

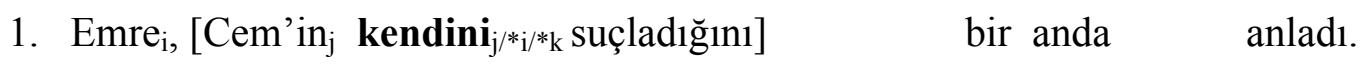
Emre Cem.GEN kendi.ACC blame.N.3SG.POSS.ACC one moment.LOC understood

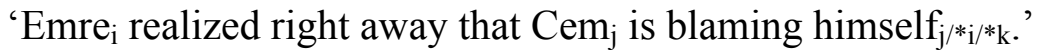

However, we should note that Sezer $(1980,1991)$ and Meral (2010) have reported that kendi can be bound by a long-distance antecedent when it is in the $3^{\text {rd }}$ grammatical singular person. Similar reports are found in Cem Değer (1996), and Yakut (2015). According to this view, the anaphor in (1) can freely refer to the matrix subject Emre, in addition to the embedded subject Cem.

Unlike English, Turkish also features the anaphor kendisi, which is unconstrained by Binding Theory: kendisi may refer to a local, long-distance or an extra-sentential antecedent, as shown in (2) (Enç 1989; Kornfilt 1997; Gürel 2002, 2004, 2006).

2. $\operatorname{Tar}_{\mathrm{i}}$, [Ömer'in $\mathrm{j}_{\mathrm{j}}$ kendisini $_{\mathrm{i} / \mathrm{j} / \mathrm{k}}$ beğendiğini] Tarık Ömer.GEN kendisi.ACC like.N.3SG.POSS.ACC quickly learned. ' Tarık $_{\mathrm{i}}$ quickly found out that Ömer $\mathrm{H}_{\mathrm{j}}$ likes himself/him/her $\mathrm{i}_{\mathrm{i} / \mathrm{k} / \mathrm{k}}$ '

Finally, Turkish also possesses the pronoun $o$, which is similar to English pronouns in that it is subject to Principle B of the Binding Theory: it may refer to an antecedent outside its local clause or to an extra-sentential antecedent, as shown in (3) (Kornfilt 1997; Meral 2013).

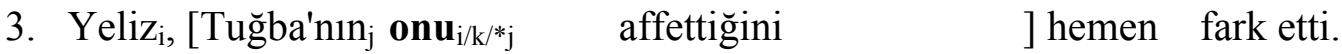
Yeliz Tuğba.GEN him/her.ACC forgive.N.3SG.POSS.ACC instantly noticed 'Yelizi instantly noticed that Tuğba ${ }_{\mathrm{j}}$ forgave him/her $/ \mathrm{h}_{\mathrm{i} / \mathrm{k} / \mathrm{j}}$.' 
It should be noted that since Turkish is a pro-drop language (Kornfilt 1984; Enç 1986; Erguvanl Taylan 1986), a further possibility is that arguments of the verb (subjects or objects) are expressed by the phonologically empty pro. The status of Turkish as a prodrop language is important because overt pronouns are interpreted differently in pro-drop and non pro-drop languages (Carminati 2002; Gürel 2002; Schimke and Colonna 2016). In pro-drop languages, the distribution of overt pronouns is more constrained than in non prodrop languages because the availability of null pronouns makes the appearance of overt pronouns marked and subject to pragmatic, information-structural constraints. In Turkish, null objects are allowed as long as appropriate discourse conditions are met, i.e. "in the presence of salient antecedents" Turan (2001: 139). For example, in (4), the object of B's response to A's question can be the null pro because a salient referent is present in the discourse (Turan 2001: 135):

4. A: Evde kek var mi?

house.loc cake exist Q

'Is there any cake at home?'

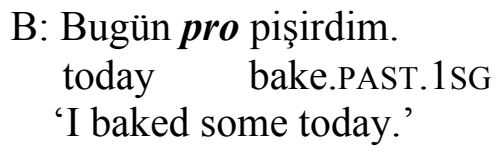

However, in the configurations presented before, such as (3) (repeated below with a null pronoun as (5)), null objects are less felicitous. In these configurations, theoretical accounts propose that null pronouns are only acceptable with extra-sentential referents and cannot refer to intra-sentential ones (Kornfilt 2007, Turan 2001). Crucially, since null pronouns are less felicitous than overt ones, the present study only focused on the overt forms. ${ }^{1}$

\section{Yeliz, [Tuğba'nın pro affettiğini ] hemen fark etti. Yeliz Tuğba.GEN forgive.N.3SG.POSS.ACC instantly noticed 'Yeliz instantly noticed that Tuğba forgave.'}

Very few studies have examined Turkish anaphors using experimental methods (Gürel, 2002, 2004; Özbek and Kahraman, 2016). To our knowledge, these studies have not focused on processing and have used untimed measures. For instance, Özbek and Kahraman (2016) tested the interpretation of kendi and kendisi using two forced preference tasks. Their materials contained sentences similar to (1-2), where the anaphor (kendi/kendisi) in the object position of an embedded clause could potentially refer to either

\footnotetext{
${ }^{1} \mathrm{We}$ independently confirmed the judgments in the literature with a group of seven native Turkish speakers. All speakers deemed null pronouns to be less felicitous than overt ones in sentences like (5) in isolation, and they judged the null pronouns as unacceptable when the sentences were embedded in dialogue contexts (see Experiment 2). For the sentences in isolation, native speakers were in agreement with the statements from the literature that the null pronoun can refer to an extra-sentential antecedent (Kornfilt, 2007; Turan, 2001). However, they also accepted coreference with the long-distance antecedent, although always deeming this option as less acceptable than the alternative with the overt pronoun.
} 
a local or a long-distance subject. The two experiments differed in whether the events described in the embedded clause made both subjects equally likely to be antecedents of the anaphor, or whether they were biased towards the long-distance antecedent. Surprisingly, the authors found that in both experiments, participants resolved kendi to local and long-distance subject at similar rates, whereas they preferred kendisi to refer to the long-distance, rather than to the local subject. One of the goals of our study was to examine whether native Turkish speakers displayed the interpretations of kendi and kendisi reported by Özbek and Kahraman (2016).

Meanwhile, Gürel (2002, 2004) examined the anaphors $o$ and kendisi using antecedent selection and truth-value judgment tasks. $O$ and kendisi were chosen due to their different syntactic constraints: $o$ in the embedded subject position cannot be bound by an intra-sentential antecedent and it can only take an extra-sentential one, whereas kendisi allows either an intra- or extra-sentential antecedents. Gürel examined the interpretation of these anaphors in isolation as well as when they were preceded by a short story. In Experiment 1, target sentences like (6) were presented in isolation:

6. Burak ${ }_{\mathrm{i}}\left[\operatorname{onun}_{*_{\mathrm{i} / \mathrm{k}}}\right.$ sinemaya gideceğini] söyledi.

Burak he/she.GEN cinema.DAT go.N.3SG.POSS said.

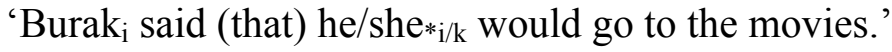

Participants were asked "Who was the person that would go to the movies?" and they had to choose between three response options: (i) Burak, (ii) some other person, or (iii) either Burak or some other person. Their judgments patterned according to the syntactic constraints of the anaphors: $o$ was assigned an extra-sentential antecedent most of the time, whereas kendisi was judged as ambiguous, allowing both intra- and extrasentential antecedents.

In a second experiment, Gürel presented similar target sentences, but they were preceded by a story that was either consistent or inconsistent with the syntactic constraint of the anaphor. For instance, in (7a) the context biased John to be the antecedent of $o$, consistently with the syntactic constraint of the anaphor.

7. a. Story context:

Mary and John went to a restaurant. Mary ordered seafood and

John ordered a pizza. The bill came to 50 dollars. John complained that the bill was high but Mary didn’t agree.

b. Mary onun restoranı pahalı bulduğunu söyledi.

Mary he/she.GEN restaurant.ACC expensive find.N.3SG.POSS.ACC said

'Mary $\mathrm{i}_{\mathrm{i}}$ said (that) he/she $*_{\mathrm{i} / \mathrm{k}}$ found the restaurant expensive.'

Participants were asked to rate ( $7 \mathrm{~b})$ as true or false: a "true" response was taken to mean that participants had settled on an extra-sentential antecedent for $o$, whereas a "false" response was taken to mean that participants had settled on an intra-sentential antecedent for $o$, an option disallowed by its syntactic constraints. Gürel observed that the context differentially affected judgments to $o$ and kendisi. For $o$, context had little influence on participants' judgments: they settled on the extra-sentential antecedent for the anaphor $96 \%$ of the time, while the intra-sentential antecedent was chosen only $4 \%$ of the time. However, judgments to kendisi showed a stronger influence of the context: kendisi was resolved 
towards the extra-sentential antecedent $21 \%$ of the time, and towards the intra-sentential antecedent $79 \%$ of the time. Thus, the effect of the preceding context was larger when the syntactic constraint of the anaphor was less restrictive.

The current study extends these previous findings in several ways. First, we examine the behavior of kendi, kendisi, and $o$ jointly, in contrast with previous studies. Second, we use a self-paced reading task to assess not only participants' judgments, but also their online reading times. Our goal is to obtain a more detailed profile of how early in processing contextual and syntactic information can affect antecedent assignment. Lastly, our experiments test the behavior of $o$, kendi, and kendisi when they are used in the object position, where their syntactic constraints have been reported to differ from those in the subject position, tested in the study by Gürel. Specifically, when $o$ is in a subject position, it cannot refer to a long-distance intra-sentential antecedent, as illustrated in (6), but this option is syntactically licit when $o$ functions as a grammatical object (Dinçtopal 2009).

\section{The current study}

Our experiments tested the behavior of kendi, kendisi, and $o$ first in isolated sentences and then in biasing contexts. Our first experiment verified the syntactic constraints proposed in the literature using an antecedent choice task: participants were asked to judge isolated sentences in order to establish their referential preferences in the absence of context. In the second experiment, the sentences with the anaphors were preceded by a dialogue that introduced a biasing context. Participants read the target sentences word-by-word and we measured their reading times and their responses to endof-sentence questions that probed for the final interpretation of the anaphors.

The biasing contexts introduced three individuals. Two of them appeared in the target sentence as potential intra-sentential antecedents of the anaphor. They occupied the positions of the embedded (local) and the matrix (long-distance) subject. Therefore, the anaphor could potentially refer to either of the two intra-sentential antecedents or to a third individual that was mentioned in the dialogue but was not present in the target sentence (extra-sentential antecedent). Target sentences were constructed separately for each anaphor and they were structured as in (1-3).

The purpose of the context was to favor an antecedent that was either compatible or incompatible with the syntactic constraints of the anaphor. For instance, in the localantecedent biasing context, illustrated in (8), the context singled out the local antecedent of the anaphor $(\mathrm{Cem})$ as the topic of the dialogue - the individual being blamed. When the anaphor in the target sentence was kendi, the context and the syntactic constraint of the anaphor were consistent, such that the dialogue made true the reading where Cem was the referent of kendi.

\section{Local biasing context}

Cem: I am so rude. I wish that I hadn't yelled at my father.

Emre: These things happen.

\section{Target sentence}


Emre realized right away that Cem is blaming kendi.

By contrast, in the long-distance biasing context the topic of the dialogue (the person being blamed) was Emre instead of Cem (e.g. Cem: You are so rude. I wish that you hadn't yelled at your father). Similarly, in the extra-sentential biasing context, the topic of the dialogue was an individual that did not appear in the target sentence (e.g. Cem: Ali is so rude. I wish that he hadn't yelled at his father). In both these contexts, the presence of kendi in the target sentence created a conflict between the syntactic constraint of the anaphor and the information provided by the context. Each anaphor appeared with the three types of context.

Our goal was to examine how these syntax-consistent or inconsistent contexts interacted with the syntactic restrictions of the anaphors. We were interested in whether participants' interpretation would be more strongly determined by the bias of the context, by the syntactic constraint of the anaphor, or by a combination of the two. In the latter case, we hypothesized that the effect of the context might be stronger for kendisi, which is not syntactically constrained and allows for local, long-distance, or extra-sentential antecedents.

\section{Experiment 1}

Experiment 1 tested the referential preferences of kendi, kendisi, and $o$ when they functioned as embedded direct objects in sentences presented without any biasing context. Participants read the sentences and had to decide whether they referred to an individual outside the sentence (the extra-sentential antecedent) or to either of the two antecedents presented within the sentence: the subject of the embedded clause (local antecedent) or the subject of the matrix clause (long-distance antecedent). We predicted that if participants obeyed the syntactic constraints proposed in the literature, then kendi should behave like a reflexive and participants should only choose the local antecedent as the referent of the anaphor. By contrast, $o$ should behave like a pronoun and participants should choose longdistance and extra-sentential, but not local antecedents. Finally, when the anaphor was kendisi, participants should choose all three response options, due to the lack of syntactic constraints on this anaphor.

\section{Methods}

\section{Participants}

Seventy-three participants were recruited from Middle East Technical University in Ankara. Four participants were excluded: three of them because they were bilingual and one because his native language was Kurdish. The remaining sixty-nine participants were entered into the analysis (mean age $=20$ years, age range $=18-23,52$ females, 61 righthanded). In this and following experiments, participants provided informed consent. All procedures were in accordance with the Declaration of Helsinki. 


\section{Materials}

Nine experimental and nine filler sentences were constructed. The experimental sentences were structured as in (8): Emre realized right away that Cem is blaming $A N A P H O R$. We selected the verb in the embedded clause to be similarly felicitous with a reflexive and a non-reflexive interpretation (e.g. blame, praise, harm). Ensuring that the verbs were similarly felicitous with both interpretations restricted the number of possible materials. Thus, we aimed to maximize experimental power by testing a large number of participants. The anaphors of interest always appeared as the direct objects of the verb. Each experimental sentence contained kendi, kendisi, or $o$, and it was followed by a question (Who was being blamed?) and three possible response options: (i) Emre (longdistance antecedent), (ii) Cem (local antecedent), (iii) Someone else (extra-sentential antecedent).

Of the nine filler items, five were referentially unambiguous while four were twoor three-way ambiguous. Like the experimental sentences, all fillers were followed by three response options. A two-way ambiguous filler is illustrated in (9):

9. Target sentence

Elif had difficulty recognizing Hülya without her glasses on.

Question

Who had no glasses on?

Response options
(a) Elif
(b) Hülya
(c) Someone else

The experimental items were distributed across three lists in a Latin Square design. Experimental and filler items were randomized for each list.

\section{Procedure}

Participants were instructed to read the items carefully and choose all possible answers. Before the experimental task, they were given a practice item that was three-way ambiguous, so as to draw their attention to the possibility that more than one response option was possible. There was no response deadline. The experiment was run on a webbased platform using Ibex Farm (Drummond, http://spellout.net/ibexfarm).

\section{Analysis}

The analysis was performed using mixed-effects logistic regressions (Jaeger 2008). We examined whether the proportion of choices of either the local, long-distance, or extrasentential antecedent differed as a function of the type of anaphor (kendi, kendisi, or $o$ ). Analyses were performed with $\mathrm{R}$, an open-source programming language and environment 
for statistical computing (R Development Core Team 2016). P-values were computed using Satterthwaite's approximation for denominator degrees of freedom with the lmerTest package (Kuznetsova, Bruun Brockhoff, and Haubo Bojesen Christensen 2014). The random effects structure of the models included random intercepts and slopes by participants and items (Barr et al. 2013). In the cases where the models failed to converge, they were gradually simplified until convergence was achieved. Non-convergence only occurred in the analysis of responses towards the extra-sentential antecedent: the simplified model only included random intercepts by participants and items. We report effect sizes using the model estimates $(\hat{\beta})$, their standard error (SE), and $z$ - and $p$-values in the tables below.

\section{Results}

Mean accuracy in the filler trials was $74 \%$. In the experimental sentences containing kendi, participants showed a clear preference for local antecedents and, unexpectedly, also for long-distance antecedents: the local antecedent was chosen on $94 \%$ of the trials, the long-distance antecedent on $85 \%$ of the trials, and the extra-sentential antecedent on $3 \%$ of the trials. When the anaphor was kendisi, participants also preferred local and long-distance antecedents over extra-sentential ones: the local antecedent was chosen on $87 \%$ of the trials, the long-distance antecedent on $96 \%$ of the trials, and the extra-sentential antecedent on $8 \%$ of the trials. Finally, in the experimental sentences containing $o$, the local antecedent was chosen on $11 \%$ of the trials, the long-distance antecedent on $96 \%$ of the trials and the extra-sentential antecedent on $81 \%$ of the trials.

FIGURE 1 shows participants' antecedent choices as a function of the type of anaphor. TABLE I shows the results of the statistical analysis. The model results showed that participants were more likely to choose the local antecedent with kendi and kendisi than with $o$. In contrast, the proportion of choices towards the long-distance antecedent did not differ as a function of the type of anaphor. Finally, the extra sentential antecedent was chosen more often for $o$ than for the other two anaphors, and more often for kendisi than for kendi.

\begin{tabular}{|c|c|c|c|c|c|c|c|c|c|c|c|c|}
\hline \multirow{2}{*}{ Antecedent choice } & \multicolumn{4}{|c|}{ Local } & \multicolumn{4}{|c|}{ Long-distance } & \multicolumn{4}{|c|}{ Extra-sentential } \\
\hline & $\beta$ & $\mathrm{SE}$ & $z$ & $p$ & $\beta$ & $\mathrm{SE}$ & $z$ & $p$ & $\beta$ & $\mathrm{SE}$ & $z$ & $p$ \\
\hline kendi vs. kendisi & -0.96 & 2.05 & -0.47 & .64 & 5.10 & 6.35 & 0.80 & .42 & 1.77 & 0.71 & 2.51 & $<.05^{*}$ \\
\hline kendi vs. o & -14.49 & 2.69 & -5.38 & $<.05 *$ & 12.67 & 7.00 & 1.81 & .07 & 13.51 & 1.99 & 6.80 & $<.05^{*}$ \\
\hline kendisi vs. o & -13.53 & 2.57 & -5.26 & $<.05 *$ & 7.57 & 8.56 & 0.88 & .38 & 12.12 & 1.97 & 6.15 & $<.05 *$ \\
\hline
\end{tabular}

TABLE I. Model results for the antecedent choice study. Model estimates $(\hat{\beta})$ and standard error $(\mathrm{SE})$ are expressed in log odds units. 


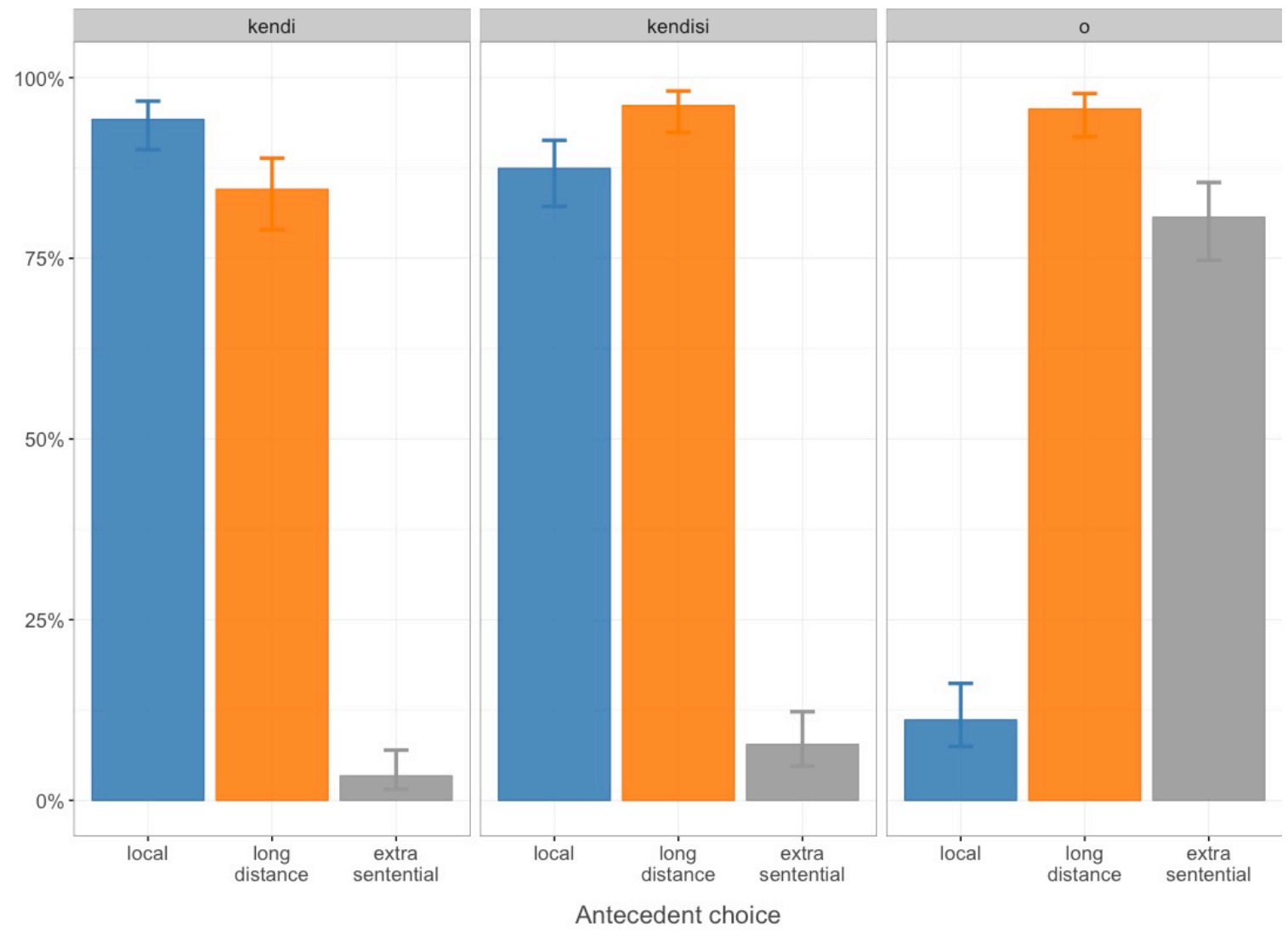

FIGURE 1. Antecedent choices in Experiment 1. Each anaphor is shown in a separate panel. Error bars show binomial 95\% confidence intervals. Note that for each anaphor, the height of the bars does not add up to $100 \%$ because multiple responses per trial were allowed.

\section{Discussion}

Experiment 1 tested whether Turkish speakers obeyed the constraints proposed in the syntactic literature when interpreting kendi, kendisi, and $o$. Our results were mostly consistent with the literature but we also found some differences. First, in the case of kendi, Turkish speakers predominantly selected local antecedents and rejected extra-sentential ones. But surprisingly, they also selected long-distance antecedents, a pattern unexpected under many syntactic accounts (Underhill 1976; Enç 1989; Kornfilt 2001; Göksel and Kerslake 2005; Rudnev 2008). However, as mentioned in the Introduction, some syntacticians have observed that kendi can be bound by long-distance antecedents when it is in the third person, as was the case for our experimental sentences (Sezer 1980, 1991; Cem Değer 1996; Meral 2010; Yakut 2015). Our results support these observations because they show that Turkish speakers were willing to resolve kendi towards long-distance antecedents in over $85 \%$ of trials. This finding is also in line with the results reported in Özbek and Kahraman (2016).

Second, kendisi was interpreted as ambiguous and allowed both local and longdistance antecedents, but the proportion of extra-sentential antecedent choices, although 
significantly higher than for kendi ( $8 \%$ vs. 3\%) was lower than what would be expected under an account where the three referents are equally likely. Interestingly, this unexpected dispreference for extra-sentential antecedents was also observed for $o$, where participants chose extra-sentential antecedents to a lesser extent than the long-distance antecedents ( $81 \%$ vs. $96 \%$ ). Under the constraints proposed in the syntactic literature for $o$, both options should have been equally likely.

Although both kendisi and $o$ were interpreted as referring to an extra-sentential antecedent to a lower degree than expected, this dispreference was more pronounced for kendisi $(8 \%)$ than for $o(81 \%)$. This result for kendisi is compatible with results reported previously (Gürel 2002; 2004). Gürel's experiment tested the interpretation of embedded subject anaphors in isolated sentences. Even though in this configuration kendisi syntactically allows extra-sentnential antecedents, Gürel's participants rejected this interpretation in $36 \%$ of the trials. Therefore, ours and Gürel's results suggest that kendisi disprefers extra-sentential antecedents due to constraints that are not syntactic in nature, a possibility that we revisit in General Discussion.

Alternatively, the dispreference towards extra-sentential antecedents might be related to the fact that, in contrast with the local and long-distance antecedents, which were introduced and assigned a name within the experimental sentences (e.g. Cem and Emre), extra-sentential antecedents only appeared in the response options identified as someone else and required participants to imagine a suitable context to license the response, which they might have found difficult.

In Experiment 2, we addressed whether participants' antecedent choices changed when the anaphors were presented within larger discourse contexts. The experimental sentences in Experiment 2 included context dialogues that clearly favored one referent (local, long-distance, extra-sentential) as the antecedent for the anaphor and thus offered insight into the question of how syntactic constraints and biasing contextual information interact during the processing of anaphors.

\section{Experiment 2}

Experiment 2 tested the sentences used in Experiment 1 when preceded by biasing contexts. Our goal was to examine how contextual and syntactic information affected participants' online processing and their ultimate choices regarding the referent of the anaphor. Based on the results from Experiment 1, we predicted different reading time patterns for each anaphor. For kendi, we expected processing difficulty when it was preceded by an extra-sentential biasing context because the information provided by the context should conflict with the syntactic constraints of the anaphor. Further, we might expect to see longer reading times for long-distance than for local contexts, as participants preferred kendi to refer to a local antecedent rather than to a long-distance antecedent. These patterns should differ for $o$, which should show processing facilitation in longdistance and extra-sentential contexts as compared with local contexts. The processing of kendisi, on the other hand, should be facilitated when preceded by local and long-distance contexts. Finally, if the dispreference towards extra-sentential antecedents observed in 
Experiment 1 reflects a true grammatical constraint of kendisi, then longer reading times should be observed in extra-sentential biasing contexts in Experiment 2.

A critical question for Experiment 2 concerned the time course of the experimental effects. Recall that in our materials, the anaphor was always used as the object of the verb within an embedded clause. Because Turkish is a verb-final language, our anaphors were followed by both the embedded and matrix verbs. Given that the meaning of the embedded verb determined whether the event described in the clause was true or false, we predicted that participants should only be able to recognize the experimental sentence as (in)appropriate given the context after encountering the embedded verb (e.g. [Emre [CP Cem ANAPHOR is blaming right away] realized], 'Emre realized right away that Cem is blaming $\left.A N A P H O R^{\prime}\right)$. This differs from previous reading studies in languages like English, where verbs precede the anaphors and the effects of interest are predicted to arise at the anaphors themselves (e.g. Badecker and Straub 2002; Sturt 2003, Chow et al. 2014). By contrast, our critical regions were the words after the anaphor, consisting of the embedded verb and following words.

Each experimental sentence was followed by an end-of-trial question that required participants to select which of the individuals mentioned in the context was the referent of the anaphor. The purpose of the question was to measure participants' ultimate interpretation of the anaphors, especially in cases where the contextual information conflicted with the syntactic constraint of the anaphor, i.e. in situations where the resolution of the anaphor towards the syntactically accessible antecedent made the sentence false in the context. The answers to these questions provided a measure of whether participants' final interpretations were guided primarily by the context or primarily by the syntax. Alternatively, under a scenario where participants' choices do not rely solely on either of these two types of information, and they are instead affected by both, we expected the influence of the context to be the largest for kendisi, which is syntactically unconstrained. By contrast, we expected the resolution of kendi and $o$ to be more strongly influenced by syntactic information.

\section{Methods}

\section{Participants}

Seventy-two participants were recruited from the Middle East Technical University in Ankara (mean age $=22$ years, age range $=18-25,56$ females, 63 right-handed). They all had normal or corrected-to-normal vision and none of them reported to be bilingual. They all provided informed consent and received course credit for their participation.

\section{Materials}

Materials consisted of twenty-seven item sets that were developed from the nine experimental items in Experiment 1. A sample of three item sets is shown in TABLE II. Each item consisted of a two-sentence dialogue context and a target sentence: nine target sentences contained kendi, nine contained kendisi, and nine contained $o$. In order to create the item sets, each context was repeated three times with minimal changes, such that it 
appeared once with kendi, once with kendisi and once with o. For instance, "hurt my mother" in item 1 (kendi) was changed to "yelled at my father" in item 10 (kendisi) and "upset my brother" in item $20(\mathrm{o})$. Crucially, the syntactic structure of the contexts and target sentences was kept identical across items. The contexts were constructed to bias participants to resolve the anaphor towards one of the three individuals mentioned in the dialogue. This bias was either compatible or incompatible with the syntactic constraints of the anaphor.

The two individuals involved in the dialogue appeared in the experimental sentence as the matrix and embedded clause subjects. Thus, the anaphor in the embedded object position could be resolved towards the two intra-sentential antecedents (local and longdistance subjects) or towards an extra-sentential antecedent (the individual not mentioned in the target sentence, but mentioned in the dialogue).

\begin{tabular}{|c|c|c|c|c|c|}
\hline \multirow[t]{2}{*}{ Item } & \multirow[t]{2}{*}{ Anaphor } & \multicolumn{3}{|c|}{ Bias } & \multirow{2}{*}{ Target Sentence } \\
\hline & & $\begin{array}{c}\text { Local } \\
\text { antecedent }\end{array}$ & $\begin{array}{l}\text { Long-distance } \\
\text { antecedent }\end{array}$ & $\begin{array}{c}\text { Extra-sentential } \\
\text { antecedent }\end{array}$ & \\
\hline 1 & Kendi & $\begin{array}{l}\text { Cem: I am so } \\
\text { rude! I wish I } \\
\text { hadn't hurt my } \\
\text { mother. } \\
\text { Emre: These } \\
\text { things happen. }\end{array}$ & $\begin{array}{l}\text { Cem: You are so } \\
\text { rude! I wish you } \\
\text { hadn't hurt your } \\
\text { mother. } \\
\text { Emre: These } \\
\text { things happen. }\end{array}$ & $\begin{array}{l}\text { Cem: Ali is so } \\
\text { rude! I wish he } \\
\text { hadn't hurt his } \\
\text { mother. } \\
\text { Emre: These } \\
\text { things happen. }\end{array}$ & $\begin{array}{l}\text { Emre realized } \\
\text { right away } \\
\text { that Cem is } \\
\text { blaming } \\
\text { kendi. }\end{array}$ \\
\hline 10 & Kendisi & $\begin{array}{l}\text { Alp: I am so } \\
\text { rude! I wish I } \\
\text { hadn't yelled at } \\
\text { my father. } \\
\text { Kaya: These } \\
\text { things happen. }\end{array}$ & $\begin{array}{l}\text { Alp: You are so } \\
\text { rude! I wish you } \\
\text { hadn't yelled at } \\
\text { your father. } \\
\text { Kaya: These } \\
\text { things happen. }\end{array}$ & $\begin{array}{l}\text { Alp: Fikret is } \\
\text { so rude! I wish } \\
\text { he hadn't yelled } \\
\text { at his father. } \\
\text { Kaya: These } \\
\text { things happen. }\end{array}$ & $\begin{array}{l}\text { Kaya realized } \\
\text { right away } \\
\text { that Alp is } \\
\text { blaming } \\
\text { kendisi. }\end{array}$ \\
\hline 20 & $\mathrm{O}$ & $\begin{array}{l}\text { Volkan: I am so } \\
\text { rude! I wish I } \\
\text { hadn't upset my } \\
\text { brother. } \\
\text { Halil: These } \\
\text { things happen. }\end{array}$ & $\begin{array}{l}\text { Volkan: You are } \\
\text { so rude! I wish } \\
\text { you hadn't upset } \\
\text { your brother. } \\
\text { Halil: These } \\
\text { things happen. }\end{array}$ & $\begin{array}{l}\text { Volkan: Selim } \\
\text { is so rude! I } \\
\text { wish he hadn't } \\
\text { upset his } \\
\text { brother. } \\
\text { Halil: These } \\
\text { things happen. }\end{array}$ & $\begin{array}{l}\text { Halil realized } \\
\text { right away } \\
\text { that Volkan is } \\
\text { blaming } o \text {. }\end{array}$ \\
\hline
\end{tabular}

TABLE II: Sample sets of experimental items in Experiment 2 
Experimental items were distributed across three lists in a Latin Square design, such that each version of an item appeared once per list and it was preceded by contexts with different bias across lists. The experimental items were combined in a pseudo-random order so that not more than three experimental items were presented consecutively. They were interspersed with 54 fillers, which also contained a two-sentence dialogue followed by a target sentence, as illustrated in (10). Half of the fillers were followed by an end-oftrial question: half of the questions asked about the context and half of them asked about the target sentence.

\section{Context}

Iskender: You look very tired. Do you have a problem?

Cem: No! I had my wedding last night. I was having fun with my friend all day long.

\section{Target sentence}

Iskender has just found out that Cem got married.

Question

Who is tired?

Response options
(a) Iskender
(b) Cem
(c) The friend

All experimental and filler sentences were divided into six regions as illustrated in (11). In the experimental sentences, the first region contained the long-distance antecedent, the second region contained the local antecedent, and the third region consisted of the anaphor region. The anaphor was followed by the embedded verb (region 4), a one- or twoword interjection (region 5), and the matrix verb (region 6). Each experimental sentence was followed by a three-option question that asked about the referent of the anaphor.

\section{Context}

Cem: I am so rude! I wish I hadn't hurt my mother.

Emre: These things happen.

\section{Target sentence}

Cem, / Emre'nin / kendini / suçladığını / bir anda / anladı.

Cem Emre.Gen kendi.ACC blame.N.3SG.POSS.ACC one moment.LOC realized 'Cem realize at once that Emre is blaming kendi.'

Question

Kendi ile kastedilen kişi kimdir?

'Who is the person referred to by kendi?'

Response options 

(a) Cem
(b) Emre
(c) the mother

\section{Procedure}

Participants were tested using a visual self-paced non-cumulative moving window design (Just et al. 1982). The experiment was controlled by the E-prime experimental software, version 1.4.1.1 (Schneider et al. 2002a, 2002b). Sentences were presented in Arial 18-point font with white letters on a black background. Each trial began with a screen where the words were masked by dashes. The first time that participants pressed the space bar, the dialogue conveying the context bias was displayed. The second key press remasked the dialogue and revealed the first word of the target sentence. Each key press revealed a word and re-masked the previous word. The reaction for each region was measured as the time difference between two successive key presses. In trials followed by an end-of-trial question, participants answered the question by pressing one of three keys. After half of the stimuli, participants were offered a break. The experiment began with instructions to read each passage as quickly and carefully as possible. Participants completed three practice items to familiarize themselves with the task. Each experimental session lasted approximately 35-40 minutes.

\section{Analysis}

Only participants with more than $70 \%$ accuracy in the filler trials were entered into the analysis. Reading times in each region were analyzed using linear mixed effects models. The regions of interest consisted of the three words following the anaphor: the embedded verb in the embedded clause, the adverb and the matrix clause verb, which was also the sentence final region. We note that reading times in sentence final regions should be interpreted with care, as they can be subject to wrap-up effects (Just and Carpenter 1980). However, due to the verb-finality of Turkish and the nature of our materials, we were not able to insert a large number of words between the embedded and the matrix verb without rendering our sentences infelicitous, and thus we chose to include the sentence final region in the analyses.

Reaction times faster than $200 \mathrm{~ms}$ or slower than $3000 \mathrm{~ms}$ were excluded. Reaction times faster than $200 \mathrm{~ms}$ are unlikely to reflect cognitive processing since the process of visual word recognition takes 200-250 ms on average (Rayner 1998; Clifton et al. 2007). Reaction times slower than $2500 \mathrm{~ms}$ are typically excluded in self-paced reading studies (Vasishth and Drenhaus 2011; Hofmeister 2011). For our study, we increased the upper boundary to $3000 \mathrm{~ms}$ to ensure that the outlier removal affected less than $10 \%$ of the data in each region. This trimming procedure affected $3.65 \%$ of the data at the anaphor region, $5.14 \%$ of the data at the embedded verb region, $4.63 \%$ of the data at the adverb region and $7.72 \%$ of the data at the matrix verb region. The appropriate transformation of the dependent variable was determined using the Box-Cox method (Box and Cox 1964; Kliegl et al. 2010) performed on the reading times pooled across regions. The reciprocal transformation was suggested as the most appropriate transformation. 
To examine responses to the end-of-trial questions, we coded answers to reflect the influence of the context bias. Responses consistent with the context bias were coded as 1 , while responses inconsistent with the context bias were coded as 0 . For instance, in items with a local biasing context, choices towards the local antecedent were coded as 1 , whereas long-distance and extra-sentential antecedent choices were coded as 0 . This coding system allowed us to quantify the success of the context in biasing participants' responses. The analyses were conducted using mixed-effects logistic regressions (Jaeger 2008).

The analysis of reading times and end-of-trial responses was done in two stages. In the first stage we examined whether the context bias of each item differentially affected participants' ratings to each type of anaphor. For this purpose, two models were compared. The first model included main effects of ANAPHOR (o/kendi/kendisi) and CONTEXT BIAS (local/long-distancelextra-sentential) but no interaction between them. By contrast, the second model assessed whether the effect of the context differed for each anaphor by including the main effects and also their interaction. The two models were compared using likelihood ratio tests to assess which model provided a better fit to the data (Baayen et al. 2008).

In the second stage, reading times for $o$, kendi, and kendisi were examined separately using a model with a fixed effect of CONTEXT BIAS (local/long-distance/extrasentential). For each anaphor, the three contexts were compared to each other: (i) local vs. long-distance biasing context, (ii) local vs. extra-sentential biasing context and (iii) longdistance vs. extra-sentential biasing context. In order to compute the first two comparisons, the local biasing context was used as a baseline and compared sequentially with the two other conditions. To compute the third comparison, the model was re-leveled and the longdistance biasing context was used as a baseline. The random structure of the models initially included random intercepts and slopes by participants and items. In the cases where the models did not converge, they were gradually simplified until convergence was achieved. In the reading time analyses, this resulted in the removal of the by-participants slopes for kendi at the adverb region and kendisi at the anaphor region. For the response choice analyses, this resulted in the removal of the by-items slopes for kendisi. We present the model estimates $(\hat{\beta})$, their standard error (SE), and $t$ - and $p$-values in the tables below.

\section{Results}

\section{Model comparison}

The model that included an interaction between the type of anaphor and the bias of the context provided a significantly better fit to the data compared to the additive model in all the critical regions (embedded verb: $\chi_{(4)}^{2}=14.01, p<.05$; adverb: $\chi_{(4)}^{2}=42.88, p<.05$; matrix verb: $\left.\chi_{(4)}^{2}=35.25, p<.05\right)$. These results show that the biasing context affected each anaphor differently, and thus the three anaphors were analyzed separately. Importantly, the model with an interaction was not significantly better than the additive

model in the pre-critical region (anaphor: $\chi_{(4)}^{2}=6.93, p=.14$ ). This shows that the differential effect of the context for each anaphor was specific to the regions of interest. 


\section{Kendi}

When kendi was preceded by an extra-sentential biasing context, participants experienced increased processing difficulty, as compared to the local biasing context. At the embedded verb, the extra-sentential condition elicited longer reading times than the local condition. This difference persisted in the two following regions, being marginal at the adverb and significant again at the matrix verb region. In addition, at the matrix verb, the extra-sentential condition also elicited significantly longer reading times than the longdistance condition. Unexpectedly, there was a difference at the anaphor region, where the extra-sentential biasing context elicited longer reading times than the local biasing context. Since the anaphor was a pre-critical region, this effect was unexpected and we examine it in the Discussion. TABLE III shows the results of the statistical analysis, and the region-byregion reading time averages are displayed in FIGURE 2.

\begin{tabular}{|c|c|c|c|c|c|c|c|c|c|c|c|c|}
\hline \multirow{2}{*}{ Region } & \multicolumn{4}{|c|}{ kendi } & \multicolumn{4}{|c|}{ kendisi } & \multicolumn{4}{|c|}{$o$} \\
\hline & $\beta$ & $\mathrm{SE}$ & $t$ & $p$ & $\beta$ & SE & $t$ & $p$ & $\beta$ & SE & $t$ & $p$ \\
\hline \multicolumn{13}{|l|}{ ANAPHOR } \\
\hline local vs. long-distance & 0.25 & 0.12 & 2.03 & .07 & 0.02 & 0.08 & 0.27 & .79 & 0.05 & 0.09 & 0.56 & .59 \\
\hline local vs. extra-sentential & 0.31 & 0.12 & 2.64 & $<.05 *$ & 0.20 & 0.10 & 2.10 & .07 & 0.12 & 0.11 & 1.15 & .28 \\
\hline long-distance vs. extra-sentential & 0.06 & 0.08 & 0.78 & .44 & 0.18 & 0.08 & 2.15 & .06 & 0.07 & 0.09 & 0.78 & .45 \\
\hline \multicolumn{13}{|l|}{ EMBEDDED VERB } \\
\hline local vs. long-distance & 0.09 & 0.09 & 1.02 & .32 & -0.16 & 0.13 & -1.17 & .29 & 0.06 & 0.17 & 0.33 & .75 \\
\hline local vs. extra-sentential & 0.30 & 0.12 & 2.52 & $<.05 *$ & 0.04 & 0.13 & 0.31 & .76 & -0.01 & 0.19 & -0.05 & .96 \\
\hline long-distance vs. extra-sentential & 0.21 & 0.14 & 1.45 & .18 & 0.20 & 0.12 & 1.58 & .16 & -0.06 & 0.12 & -0.53 & .61 \\
\hline \multicolumn{13}{|l|}{ ADVERB } \\
\hline local vs. long-distance & -0.01 & 0.10 & -0.07 & .95 & -0.11 & 0.16 & -0.67 & .53 & -0.18 & 0.16 & -1.14 & .29 \\
\hline local vs. extra-sentential & 0.25 & 0.12 & 2.00 & .08 & 0.06 & 0.16 & 0.40 & .70 & -0.48 & 0.17 & -2.89 & $<.05^{*}$ \\
\hline long-distance vs. extra-sentential & 0.25 & 0.17 & 1.50 & .17 & 0.17 & 0.15 & 1.16 & .28 & -0.30 & 0.15 & -2.01 & .09 \\
\hline \multicolumn{13}{|l|}{ MATRIX VERB } \\
\hline local vs. long-distance & -0.07 & 0.14 & -0.48 & .64 & -0.24 & 0.16 & -1.56 & .16 & 0.04 & 0.17 & 0.24 & .81 \\
\hline local vs. extra-sentential & 0.36 & 0.13 & 2.80 & $<.05 *$ & -0.10 & 0.17 & -0.59 & .57 & -0.24 & 0.22 & -1.12 & .30 \\
\hline long-distance vs. extra-sentential & 0.42 & 0.14 & 3.01 & $<.05 *$ & 0.14 & 0.21 & 0.66 & .53 & -0.29 & 0.14 & -2.01 & .09 \\
\hline
\end{tabular}

TABLE III. Linear mixed-effects model results for the regions of interest in Experiment 2. Model estimates $(\hat{\beta})$ and standard error (SE) are expressed in reciprocal units. 


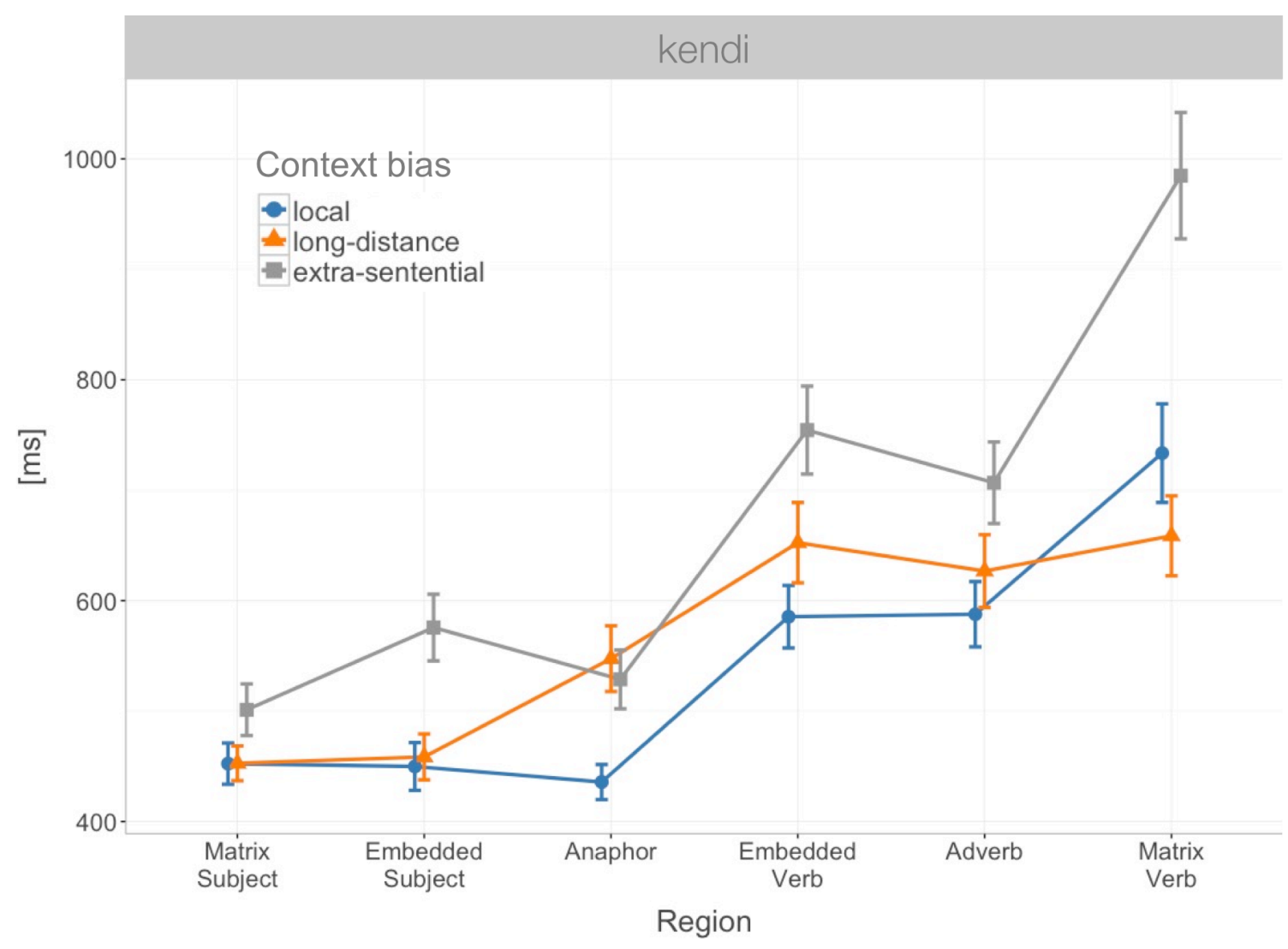

FIGURE 2. Region-by-region reading times averages for kendi in Experiment 2. Error bars indicate the standard error of the mean.

\section{Kendisi}

No differences between conditions were found in any of the regions of interest. These results suggest that the processing of kendisi did not differ as a function of the context that preceded the anaphor. The region-by-region reading time averages for kendisi are shown in FigURE 3. 


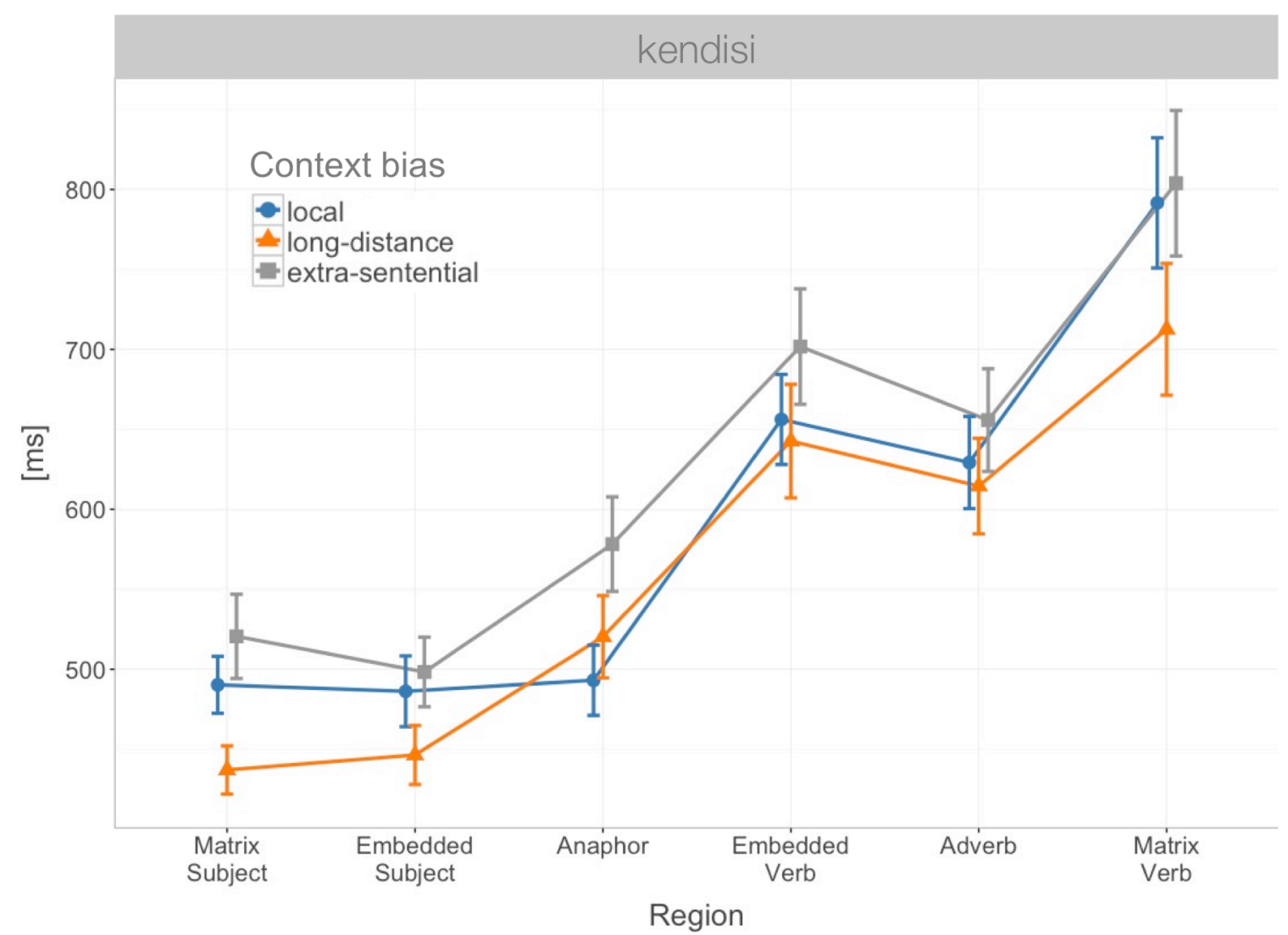

FIGURE 3. Region-by-region reading time averages for kendisi in Experiment 2. Error bars indicate the standard error of the mean.

\section{$O$}

When $o$ was preceded by a local biasing context, participants experienced increased processing difficulty, as compared to the extra-sentential biasing context. These results, however, were restricted to the adverb region, where the local context condition elicited significantly longer times than the extra-sentential context. Although the same pattern was observed in the matrix verb region, it did not reach significance. No differences between conditions were found at the anaphor or embedded verb regions. The region-by-region reading time averages for $o$ are shown in FIGURE 4. 


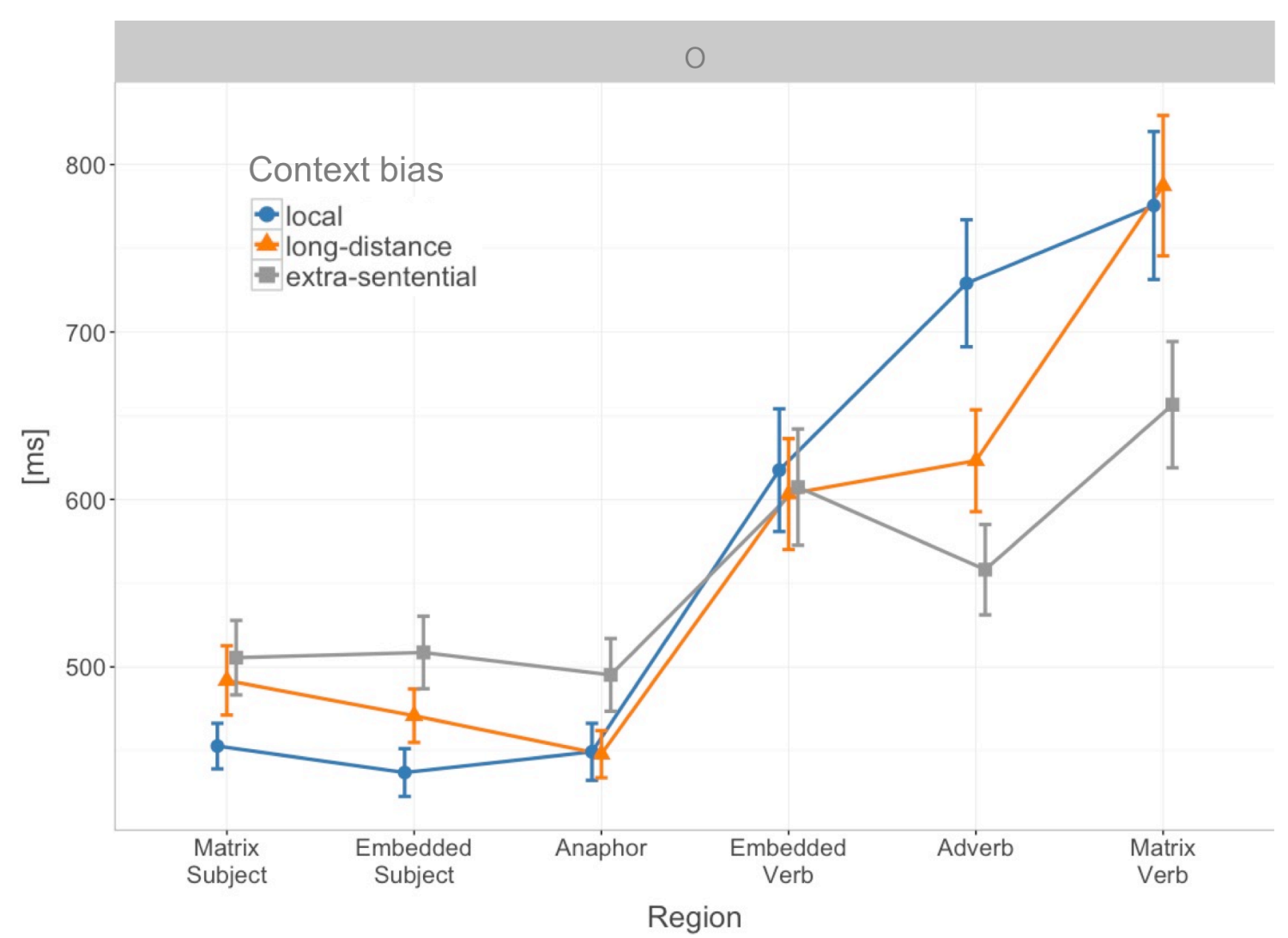

FIGURE 4. Region-by-region reading time averages for $o$ in Experiment 2. Error bars indicate the standard error of the mean.

\section{Responses}

Response accuracy in the filler trials was $94 \%$ and no participants were excluded due to low accuracy. Responses in the experimental trials were coded to reflect the effect of context on antecedent choices. Responses consistent with the context bias were coded as 1 , while responses inconsistent with the context bias were coded as 0 . FIGURE 5 shows the proportion of responses towards the antecedent consistent with the context as a function of the context bias. For instance, for kendi, the first bar shows the proportion of trials where participants chose the local subject in the local biasing context condition. Similarly, the second bar shows the proportion of long-distance subject choices in the long-distance biasing context, and the third bar shows the proportion of extra-sentential subject choices in the extra-sentential biasing context. Thus, the height of the bars measures the "success" of the context in directing participants' interpretation towards the antecedent consistent with the context.

As with the reading times, the effect of the context bias differed for each anaphor. This was supported by the comparison between the additive an interactive models, where the model that included an interaction between the type of anaphor and the bias of the context provided a significantly better fit to the data than the additive model $\left(\chi_{(4)}^{2}=130.14\right.$, $p<.05)$. Therefore, the effect of the context bias was analyzed separately for each anaphor. TABLE IV shows the results of the statistical analysis. 
When the anaphor was kendi, participants chose the local antecedent on $79 \%$ of the trials (in the local biasing context), the long-distance antecedent on $68 \%$ of the trials (in the long-distance biasing context) and the extra-sentential antecedent on $55 \%$ of the trials (in the extra-sentential biasing context). The model results showed that participants were equally likely to choose the local and long-distance antecedents when they were consistent with the context. Further, they were significantly less likely to choose the extra-sentential antecedent, even when biased by the context, as compared with the local biasing context condition.

When the anaphor was kendisi, participants chose the local antecedent on $78 \%$ of the trials (in the local biasing context), the long-distance antecedent on $74 \%$ of the trials (in the long-distance biasing context) and the extra-sentential antecedent on $59 \%$ of the trials (in the extra-sentential biasing context). As with kendi, the model results showed that participants were equally likely to choose the local and long-distance antecedents when they were consistent with the context. Further, they were significantly less likely to choose the extra-sentential antecedent, even when biased by the context, as compared with the local biasing context condition.

When the anaphor was $o$, participants chose the local antecedent on $42 \%$ of the trials (in the local biasing context), the long-distance antecedent on $74 \%$ of the trials (in the long-distance biasing context) and the extra-sentential antecedent on $79 \%$ of the trials (in the extra-sentential biasing context). The model results showed that participants were equally likely to choose the extra-sentential and long-distance antecedents when they were biased by the context. Both these conditions differed significantly from local antecedent choices in the local biasing context.

\begin{tabular}{|c|c|c|c|c|c|c|c|c|c|c|c|c|}
\hline \multirow{2}{*}{ Responses } & \multicolumn{4}{|c|}{ kendi } & \multicolumn{4}{|c|}{ kendisi } & \multicolumn{4}{|c|}{$o$} \\
\hline & $\beta$ & SE & $z$ & $p$ & $\beta$ & $\mathrm{SE}$ & $z$ & $p$ & $\beta$ & SE & $z$ & $p$ \\
\hline local vs. long-distance & -0.69 & 0.67 & -1.03 & .30 & -0.29 & 0.23 & -1.24 & .21 & 1.73 & 0.51 & 3.38 & $<.05^{*}$ \\
\hline local vs. extra-sentential & -1.46 & 0.45 & -3.20 & $<.05 *$ & -0.75 & 0.29 & -2.57 & $<.05 *$ & 2.12 & 0.58 & 3.62 & $<.05^{*}$ \\
\hline long-distance vs. extra-sentential & -0.77 & 0.40 & -1.93 & .05 & -0.46 & 0.30 & -1.52 & .13 & 0.39 & 0.36 & 1.07 & .29 \\
\hline
\end{tabular}

TABLE IV. Model results for after-the-trial responses in Experiment 2. Model estimates $(\hat{\beta})$ and standard error (SE) are expressed in log odds. 


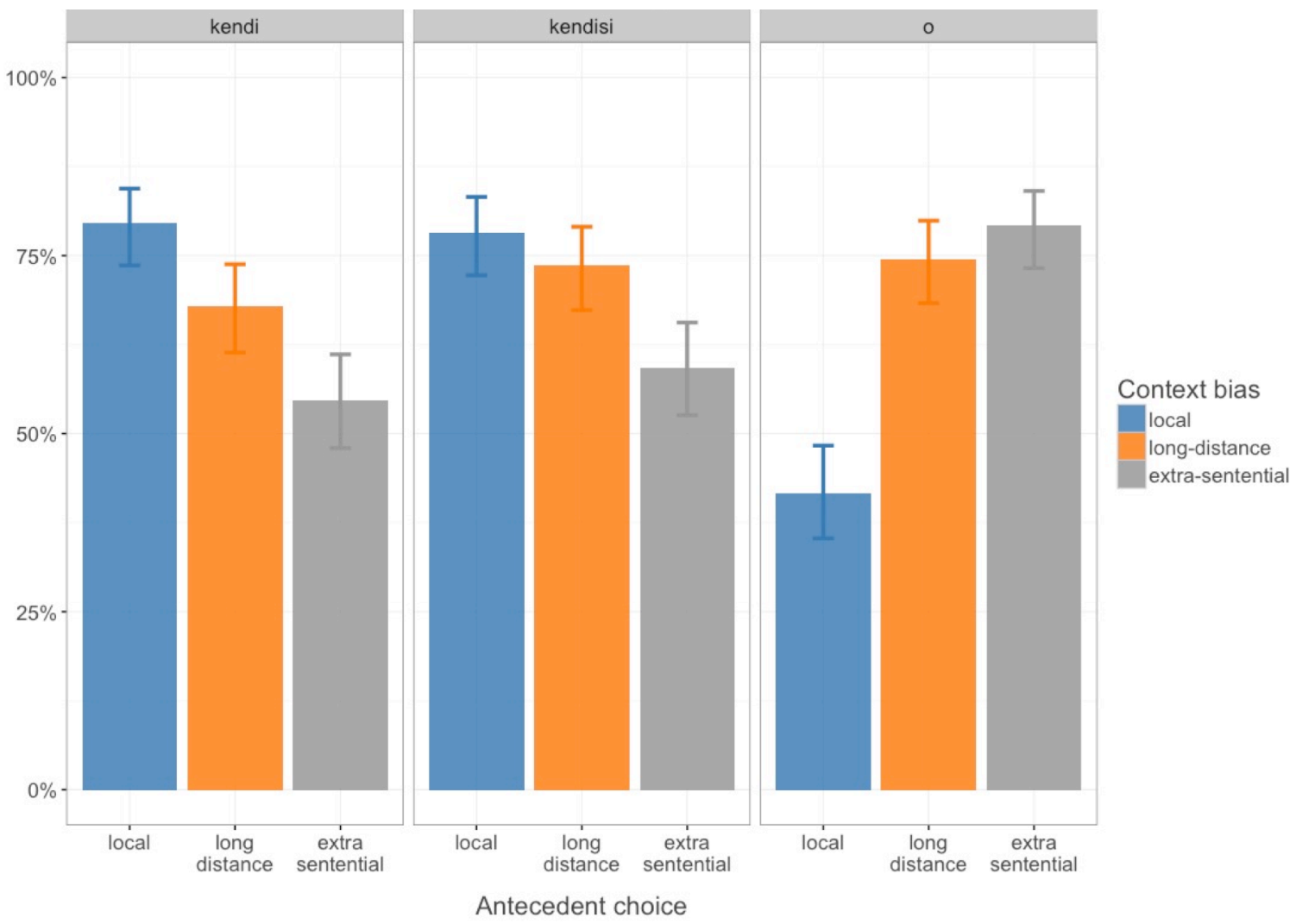

FIGURE 5. Participants' end-of-trial antecedent choices as a function of the bias of the context in Experiment 2. Each anaphor is shown in a separate panel. The height of the bars reflects the proportion of responses that were consistent with the context bias. Error bars show bootstrapped 95\% confidence intervals.

\section{Discussion}

Experiment 2 examined the effect of a biasing context on the processing and interpretation of kendi, kendisi, and $o$. We were interested in how the anaphors were resolved in situations where the context favored an antecedent that was syntactically either accessible or inaccessible. The results of the model comparisons showed that the interpretation of the anaphors was differentially affected by each type of context. This was observed in the reading times after each anaphor and in the responses to end-of-trial questions. The response time analyses showed that the processing of kendisi did not differ according to the bias of the context, suggesting that it was equally easy for participants to interpret kendisi as co-referential with any of the three possible antecedents. By contrast, speakers showed processing difficulty for kendi and $o$ when the contexts biased a syntactically inaccessible antecedent, namely the extra-sentential antecedent for kendi and the local antecedent for $o$. These results suggest that contextual information affected the online processing of kendisi to a greater extent than it did kendi or $o$. We believe that this pattern is consistent with contextual information having a greater impact on the interpretation of anaphors when they are unconstrained by syntax than when they are syntactically constrained. 
In contrast with Experiment 1, where the extra-sentential antecedent was dispreferred for kendisi and $o$, no such dispreference was observed in the reading time analyses in Experiment 2. For kendisi, speakers did not show processing difficulty in the extra-sentential biasing condition in any region. Similarly, when the anaphor was $o$, speakers read the critical and post-critical regions more quickly in the extra-sentential condition. However, as a reviewer pointed out, in the extra-sentential biasing condition, the extra-sentential antecedent was not only explicitly mentioned, but also favored by the context, which may have further facilitated the processing of the anaphor. It therefore remains an open question whether kendisi (and to an extent $o$ ) can refer to an extrasentential antecedent when such an antecedent is explicitly mentioned, but not favored by the context. Further research will be necessary to address this issue.

As in Experiment 1, the reading patterns for kendi showed that participants accepted not only local, but also long-distance antecedents (Sezer 1980, 1991; Meral 2010, Özbek and Kahraman 2016): speakers were slower to read kendi and the following regions in contexts that favored the extra-sentential antecedent than in contexts that favored the local or long-distance antecedents. However, one unexpected result in the processing of kendi was that reading times in the extra-sentential context were significantly longer than in the local context already at the anaphor region. At this region, no effects were expected because the information that allowed participants to detect a conflict between the syntactic constraints of the anaphor and contextual information was only available at the following embedded verb, blamed (e.g. Cem, Emre kendi blamed realized). Further, the processing difficulty associated with extra-sentential contexts was also numerically present in the precritical regions for kendisi and $o$, as shown in FIGURES 3 and 4, although it was only significant at the anaphor for kendi. Thus, the extra-sentential contexts seemed harder to process regardless of the anaphor.

One possible explanation for this pattern is that it resulted from differences in the reading of the dialogues themselves. Although the dialogues had a similar syntactic structure in the local, long-distance and extra-sentential contexts, there were lexical differences between them that may have rendered the extra-sentential context more difficult. For instance, the local and long-distance conditions contained first and second person pronouns (e.g. Cem: I am/you are so rude! I wish I/you hadn't hurt my/your mother), but the extra sentential condition contained proper names (e.g. Ali). Since proper names are often longer and less frequent than pronouns, they may have elicited longer reading times, which may have spilled over to the target sentence. In addition, the proper names introduced an additional discourse referent, which may have rendered the dialogues more complex and thus harder to process as compared to the other two contexts.

To address this hypothesis, we computed a post-hoc analysis of the reading times for the dialogues region. These averages are shown in TABLE V. Reading times for extrasentential contexts were always longer than for the other two, which supports our suggestion that differences in the initial regions of the target sentences may have resulted from spillover effects. Crucially, although these spillover effects complicate the interpretation of the sentence initial regions, our conclusions were always based on the later regions, and the lack of any significant differences at the anaphor region for kendisi and $o$ suggests that these spillover effects had likely disappeared by the time participants read the anaphors. 


\begin{tabular}{rccc}
\hline \multirow{3}{*}{ Biasing Context } & \multicolumn{3}{c}{ Anaphor } \\
\cline { 2 - 4 } & kendi & kendisi & o \\
\cline { 2 - 4 } Local & $7268(277)$ & $7109(229)$ & $7473(265)$ \\
Long-distance & $7367(271)$ & $8796(407)$ & $8750(367)$ \\
Extra-sentential & $8490(348)$ & $9044(366)$ & $9735(377)$ \\
& & & \\
\hline
\end{tabular}

TABLE V. Dialogue reading time averages for Experiment 2.

Another important goal of Experiment 2 was to identify speakers' ultimate anaphor interpretation in cases where contextual and syntactic information conflicted. The responses to the end-of-trial questions show that participants' final interpretation was consistent with the syntactic constraints revealed in Experiment 1. For each anaphor, participants chose the syntactically accessible antecedent(s) at the highest percent in the contexts that favored such antecedent(s). In other words, the anaphor kendi was resolved towards the local antecedent in the context that favored this antecedent significantly more frequently ( $75 \%$ of the trials) than it was resolved towards the extra sentential antecedent in contexts with an extra sentential bias (55\% of the trials). When the anaphor was $o$, participants chose the extra sentential antecedent as the referent of the anaphor in $79 \%$ of the trials where the context favored this antecedent. Similarly, the long-distance subject was chosen in $74 \%$ of the trials in contexts with a long distance bias, in contrast with the local subject, which was chosen as the referent of $o$ on only $42 \%$ of the trials in contexts with the local bias. Finally, kendisi was resolved towards the context-biased antecedent in $79 \%$ of the trials in contexts that favored the local subject, in $74 \%$ of the trials in contexts that favored the long distance antecedents, and in 59\% of the trials in contexts that favored an extra-sentential antecedent (revealing the re-emergence of the dispreference towards the extra-sentential antecedents which we observed in Experiment 1, but not in the processing study).

These results suggest that speakers prefer to interpret anaphors in context in a way that is consistent with their syntactic constraints. Nevertheless, the biasing contexts were able to override the syntactic constraints of the anaphors on some trials, when they were willing to disregard the syntactic restrictions on the anaphor in order to accommodate the bias of the context: each anaphor was judged as referring to the antecedent favored by the context at least $40 \%$ of the time, even when the antecedent was syntactically inaccessible. For example, $o$ was co-referential with the local antecedent $42 \%$ of the time in contexts that favored this antecedent (compared to $11 \%$ in isolated sentences in Experiment 1) and in contexts that favored the extra-sentential antecedent, kendi was interpreted as coreferential with this antecedent $55 \%$ of the time (compared to 3\% in Experiment 1 ). We discuss the implications of these results in the General Discussion. 


\section{General Discussion}

Our study had two goals: first, we were interested in assessing the referential possibilities of Turkish anaphors, which is an issue that has received substantial attention in theoretical literature but less so in psycholinguistic studies (for exceptions, see Gürel 2004, 2006 and Özbek and Kahraman 2016). Second, we wanted to examine how these syntactic constraints interacted with contextual information. We collected untimed judgments to assess the syntactic restrictions of the anaphors and we conducted an online experiment to address how the anaphors were processed when preceded by contextual information that was consistent or inconsistent with their syntactic constraints. These two issues are discussed below.

\section{The syntactic constraints of Turkish anaphors}

The results of our experiments partially supported the claims in the theoretical literature about the referential possibilities of kendi, kendisi, and $o$. Consistent with the literature, kendi preferred local antecedents and $o$ dispreferred them. This behavior was observed for both sentences in isolation and in context and it affected speakers' judgments and reading times. Further, we observed that kendisi could corefer with both local and longdistance antecedents.

However, we also observed some unexpected patterns. For kendi, we found that it could also refer to a long-distance antecedent. This finding is consistent with some theoretical and experimental studies (Sezer 1980, 1991; Cem Değer 1996; Meral 2010; Yakut 2015; Özbek and Kahraman 2016), but it is unpredicted by others (Underhill 1976; Enç 1989; Kornfilt 2001; Göksel and Kerslake 2005). Further, in Experiment 1, speakers were reluctant to consider extra-sentential antecedents for kendisi and $o$ : such antecedents were dispreferred for kendisi and they were preferred for $o$ to a lesser extent than longdistance antecedents. However, the dispreference for extra-sentential antecedents disappeared for $o$ in Experiment 2, both in the reading times and the end-of-trial responses. This suggests that it may have arisen in Experiment 1 due to a combination of factors: first, the experimental items were presented in isolation and second, the extra-sentential antecedent did not have a specific referent in the text and was only identified as 'someone else' in the response options.

For kendisi, the dispreference towards extra-sentential antecedents was not observed in reading times, although it appeared in participants' responses to the end-oftrial questions. Therefore, the joint results of Experiment 1 and the questions of Experiment 2 suggest that kendisi might indeed prefer intra- to extra-sentential antecedents. However, the fact that the extra-sentential dispreference was not found in the reading times suggests a weaker constraint than those restricting kendi and $o$. We suggest that this might reflect a pragmatic, rather than a syntactic dispreference. This possibility would be in line with some previous studies that have sought to explain the distribution of kendisi in terms of pragmatics. For example, Sezer (1980) proposed that kendisi is used when speakers wish to convey psychological distance or lack of empathy between themselves and the referent of the anaphor. Similarly, Enç (1983) reported that in cases where kendisi is not bound 
within a sentence, it "must pick out an individual that is already in the domain of discourse, and cannot be used to introduce an individual into the domain of discourse". (pg. 85)

Under both accounts, the use of kendisi to refer to an extra-sentential antecedent, although syntactically available, must satisfy some pragmatic constraints, such as a lack of empathy between the speaker and the extra-sentential referent or the availability of the referent in the listeners' discourse representation. In our materials, no individual corresponding to the extra-sentential antecedent was present in Experiment 1 and in Experiment 2, the fact that the extra-sentential referent was absent from the target sentence may have made it less salient than the local and long-distance antecedents. Therefore, the pragmatic conditions for using kendisi to felicitously refer to an extra-sentential antecedent may not have been met, which would account for participants' ultimate dispreference towards this option in the end-of-trial questions. Crucially, however, the pronoun $o$ has not been reported to be subject to additional pragmatic constraints and the lack of such restrictions may be responsible for the fact that the dispreference for extra-sentential antecedents for $o$ were less pronounced in Experiment 1 and absent in Experiment 2.

\section{The interpretation of Turkish anaphors in context}

We considered three possible ways in which syntactic and contextual information could interact in cases of information conflict. According to the first two, the referent of an anaphor might be fully determined by the syntax or fully determined by the context. Under the first possibility, participants may disregard contextual information when it conflicts with the syntactic constraints of the anaphor, which should be crucial in guiding their interpretation because they reflect stable grammatical properties. This pattern has been observed in processing studies of English reflexives, which have found that in cases where syntactic and morphological cues (e.g. gender and number) conflict, native speakers prioritize syntactic cues, at least in the initial stages of coreference (e.g. Sturt 2003; Xiang et al. 2009; Felser \& Cunnings 2012).

Alternatively, the interpretation of Turkish anaphors may be predominantly guided by contextual information, which may override syntactic constraints in cases of conflict. Although we are not aware of an explicit formulation of this account, it builds on findings showing that discourse knowledge plays a key role in determining the interpretation of an anaphor (e.g. Kaiser 2016). Finally, both contextual and syntactic information might jointly guide coreference (Gordon and Scearce 1995; Gürel 2004, 2006; Li and Kaiser 2009). We considered a specific variant of this third possibility under which the effect of contextual information should be larger for syntactically unconstrained (kendisi) than syntactically constrained anaphors (kendi and $o$ ).

Participants' answers to the end-of-trial questions of Experiment 2 argue against the first two possibilities outlined above. If speakers' responses had relied solely on their syntactic constraints, syntactically unlicensed antecedents should have never been chosen. However, in Experiment 2, participants chose syntactically inaccessible antecedents to a certain extent when they were biased by the context: extra-sentential antecedents were chosen for kendi $55 \%$ of the time and local antecedents were chosen for $o 42 \%$ of the time. Compared with the frequency of the same choices when the sentences appeared in isolation in Experiment 1 (3\% and 11\% respectively), these results show that speakers were more 
likely to select a syntactically illicit antecedent when it was supported by contextual information.

If, on the other hand, the bias of the context had fully determined participants' answers, we should not have observed any differences between the referents chosen for different anaphors: speakers should have been equally likely to choose the antecedent favored by the context regardless of whether the anaphor was kendi, kendisi, or $o$. However, the existence of different proportions of antecedent choices across anaphors suggests that participants' responses were not guided solely by contextual information, but that the syntactic constraints of the anaphors also played a role. This result supports previous findings on English, Chinese, and French, which have shown that both contextual and syntactic information affect the resolution of anaphors (Gordon and Scearce 1995; Li and Kaiser 2009; Kaiser and Cherqaoui 2016).

The reading time patterns in Experiment 2 also suggest that the interaction between syntactic and contextual information depends on the extent to which an anaphor is syntactically constrained. Specifically, when the biasing context favored a syntactically unlicensed antecedent for kendi and $o$, longer reading times were observed, consistent with increased processing difficulty. By contrast, participants did not show any processing difficulty for kendisi in any of the three biasing contexts. This suggests that speakers were able to effortlessly use contextual information to compute coreference for kendisi, even with extra-sentential antecedents, which were dispreferred in the judgments of Experiment 1 and the end-of-trial responses of Experiment 2.

Our results are also consistent with studies examining the processing of other phenomena, such as relative clauses (Yang et al. 2012) and lexical ambiguities (de Almeida and Libben 2014). For instance, Yang and colleagues showed that object relative clauses incur processing difficulties in isolation, but not if they are preceded by a context that biases participants' syntactic parse towards an object clause construction. Similarly, de Almeida and Libben showed that when placed in a sentential context, ambiguous words, such as unlockable ('able to be unlocked' / 'unable to be locked') are resolved so as to be consistent with the context, while in isolation their disambiguation is determined by word-internal factors.

Our study extends these findings by testing situations where the interpretation favored by the context was incompatible with speakers' syntactic knowledge about the anaphors. We found that in such situations, the bias of the context influenced, but did not fully override syntactic constraints. One question that arises is whether the constraining role of syntax on contextual information is specific to anaphor interpretation or can be generalized to other ambiguity phenomena. For example, to what extent would a biasing context affect the quantifier raising possibilities of quantifiers contained within a syntactic island from which movement is otherwise disallowed? Or would the bias of the context be able to cancel (or at least ameliorate) crossover effects found in sentences where the whword is found to the left of a co-referential pronoun (e.g. $* W h o_{i}$ does he $e_{i}$ love?)? Further research on the interaction between syntax and contextual information in the interpretation of different phenomena might help shed light on the question of whether some kinds of information are inherently prioritized for ambiguity resolution during language processing. 


\section{Conclusion}

This paper examined the processing of Turkish, a language with a tripartite system of anaphors, to address the question of how contextual and syntactic information affect anaphor resolution. Jointly, the results from an antecedent selection and a self-pacedreading task suggest that both syntactic and contextual information guide speakers' interpretation of anaphors. Further, we found that Turkish speakers were more strongly influenced by biasing contextual information in the processing of syntactically unconstrained (kendisi) than syntactically constrained anaphors (kendi, o). We conclude that contextual information affects the interpretive possibilities associated with an anaphor, but that the influence of context crucially depends on the degree to which an anaphor is syntactically constrained.

\section{References}

Baayen, R. H., Davidson, D. J., \& Bates, D. M. (2008). Mixed-effects modeling with crossed random effects for subjects and items. Journal of Memory and Language, 59, 390-412.

Badecker, W., \& Straub, K. (2002). The processing role of structural constraints on the interpretation of pronouns and anaphora. Journal of Experimental Psychology: Learning, Memory, and Cognition, 28, 748-769.

Box, G. E. P., \& Cox, D. R. (1964). An analysis of transformations. Journal of the Royal Statistical Society, Series B (Methodological), 26, 211-252.

Carminati, M. N. (2002). The processing of Italian subject pronouns. Unpublished doctoral dissertation, University of Massachusetts.

Cem Değer, A. (1996) Türkçedeki dönüşlü adılların yönetici ulamlarının tanımlanması. In L. Oktar and A. Cem Değer (Eds.), X. Dilbilim Kurultayı Bildirileri (pp. 41-47).

Chen H-C., Cheung H., Tang S., \& Wong Y. (2000). Effects of antecedent order and semantic context on Chinese pronoun resolution. Memory and Cognition, 28, $427-438$.

Chomsky, N. (1981). Lectures on Government and Binding. Dordrecht: Foris.

Chow, W. Y., Lewis, S., \& Phillips, C. (2014). Immediate sensitivity to structural constraints in pronoun resolution. Frontiers in Psychology, 5, 1-16.

Clifton, C., Jr., Kennison, S. M., \& Albrecht, J. (1997). Reading the words 'her', 'his', and 'him': Implications for parsing principles based on frequency and structure. Journal of Memory and Language, 36, 276-292. 
Clifton, C., Jr., Frazier, L., \& Deevy, P. (1999). Feature manipulation in sentence comprehension. Rivisita di Linguistica, 11, 11-39.

Clifton, C., Jr., Staub, A., \& Rayner, K. (2007). Eye movements in reading words and sentences. In R. P. G. van Gompel, M. H. Fischer, W. S. Murray, \& R. L. Hill (Eds.), Eye movements: A window on mind and brain (pp. 341-372). Amsterdam, The Netherlands: Elsevier.

Cozijn, R., Commandeur, E., Vonk, W., \& Noordman, L. G. M. (2011). The time course of the use of implicit causality information in the processing of pronouns: A visual world paradigm study. Journal of Memory and Language, 64, 381-403.

de Almeida, R. G. \& Libben, G. (2005). Changing morphological structures: The effect of sentence context on the interpretation of structurally ambiguous English trimorphemic words. Language and Cognitive Processes, 20, 373-394.

Dinçtopal, N. (2009). Anaphora in Turkish. Linguistics in the Big Apple: CUNY/NYU Working Papers in Linguistics. Retrieved from: http://www.gc.cuny.edu/CUNY_GC/media/CUNY-GraduateCenter/PDF/Programs/Linguistics/LIBA/NazikDinctopal_AnaphoraInTurkish_LI BA.PDF

Enç, M. (1983). Anchored Expressions. In M. Barlow, D. P. Flickinger, \& M. T. Westcoat (Eds.), Proceedings of The West Coast Conference on Formal Linguistics 2 (pp. 79-88). Stanford: Stanford Linguistic Association.

Enç, M. (1986). Topic switching and pronominal subjects in Turkish. In D. Slobin \& K. Zimmer (Eds.) Typological studies in language 8: Studies in Turkish linguistics (pp. 195-208). Amsterdam: John Benjamins.

Enç, M. (1989). Pronouns, licensing, and binding. Natural Language and Linguistic Theory, 7, 51-92.

Erguvanlı Taylan, E. (1986). Pronominal versus zero representation of anaphora in Turkish. In D. Slobin \& K. Zimmer (Eds.) Typological studies in language 8: Studies in Turkish linguistics (pp. 209-233). Amsterdam: John Benjamins.

Featherstone, C. R., \& Sturt, P. (2010). Because there was a cause for concern: An investigation into a word-specific prediction account of the implicit-causality effect. The Quarterly Journal of Experimental Psychology, 63, 3-15.

Felser, C., \& Cunnings, I. (2012). Processing reflexives in a second language: The timing of structural and discourse-level constraints. Applied Psycholinguistics, 33, 571603. 
George, L. M., \& Kornfilt, J. (1981). Finiteness and boundedness in Turkish. In F. W. Heny (Ed.), Binding and Filtering (pp. 105-128). Cambridge, MA: MIT Press.

Gernsbacher. M. A., \& Hargreaves, D. J. (1988). Accessing sentence participants: The advantage of first mention. Journal of Memory and Language, 27, 699-717.

Gernsbacher, M. A., Hargreaves, D. J., \& Beeman, M. (1989). Building and accessing clausal representations: The advantage of first mention versus the advantage of clause recency. Journal of Memory and Language, 28, 735-755.

Gordon, P. C., \& Scearce, K. A. (1995). Pronominalization and discourse coherence, discourse structure and pronoun interpretation. Memory and Cognition, 23, 313323.

Göksel, A., \& Kerslake, C. (2005). Turkish: A Comprehensive Grammar. New York: Routledge.

Gürel, A. (2002). Linguistic characteristics of second language acquisition and first language attrition: Turkish overt versus null pronouns. (Doctoral dissertation). McGill University.

Gürel, A. (2004). Selectivity in L2-induced L1 attrition: a psycholinguistic account. Journal of Neurolinguistics, 17, 53-78.

Gürel, A. (2006). L2 acquisition of pragmatic and syntactic constraints in the use of overt and null subject pronouns. In R. Slabakova, S. A. Montrul, \& P. Prévost (Eds.), Inquiries in Linguistic Development: In honor of Lydia White (pp. 259-282). Amsterdam/Philadelphia: John Benjamins.

Hofmeister, P. (2011). Representational complexity and memory retrieval in language comprehension. Language and Cognitive Processes, 26, 376-405.

Just, M. A., and Carpenter P. A. (1980). A theory of reading: From eye fixations to comprehension. Psychological Review, 87, 329-354.

Just, M. A., Carpenter, P. A., \& Woolley, J. D. (1982). Paradigms and processes in reading comprehension. Journal of Experimental Psychology: General, 111, 228-238.

Kaiser, E. (2016). Discourse level processing. In P. Knoeferle, P. Pyykkönen-Klauck, \& M. W. Crocker (Eds.), Visually situated language comprehension. Amsterdam: John Benjamins.

Kaiser, E. \& Cherqaoui, B. (2016). Effects of coherence on anaphor resolution, and vice versa: Evidence from French personal pronouns and anaphoric demonstratives. In A. Holler \& K. Suckow (Eds.), Empirical Perspectives on Anaphora Resolution (pp.51-78). Berlin, Boston: Mouton De Gruyter. 
Kennison, S. M. (2003). Comprehending the pronouns her, him, and his: Implications for theories of referential processing. Journal of Memory and Language, 49, 335-352.

Kliegl, R., Masson, M. E. J., \& Richter E. M. (2010). A linear mixed model analysis of masked repetition priming. Visual Cognition, 18, 655-681.

Koornneef, A. W., \& Van Berkum, J. J. A. (2006). On the use of verb-based implicit causality in sentence comprehension: Evidence from self-paced reading and eye tracking. Journal of Memory and Language, 54, 445-465.

Kornfilt, J. (1984). Case marking, agreement, and empty categories in Turkish. Unpublished doctoral dissertation, Harvard University.

Kornfilt, J. (1997). Turkish. London, New York: Routledge.

Kornfilt, J. (2001). Local and long-distance reflexives in Turkish. In P. Cole, G. Hermon, \& J. C.-T. Huang (Eds.) Long-distance reflexives (pp. 197-225). New York: Academic Press.

Kornfilt, J. (2007). Review: Case, referentiality and phrase structure by Balkız Öztürk. Journal of Linguistics 43 (3): 736-742.

Lee, M. W., \& Williams, J. N. (2008). The role of grammatical constraints in intrasentential pronoun resolution. Unpublished manuscript. London Metropolitan University and Cambridge University.

Li, D. C.-H., \& Kaiser, E. (2009). Overcoming structural preference: Effects of context on the interpretation of the Chinese reflexive Ziji. In S. L. Devi, A. Branco and R. Mitkov (Eds.), Proceedings of the 7th Discourse Anaphora and Anaphor Resolution Colloquium (DAARC 2009) (pp. 64-72). AU-KBK Research Centre, Anna University.

Maratsos, M. P. (1973). The effects of stress on understanding pronominal coreference in children. Journal of Psycholinguistic Research, 1, 1-8.

Meral, H. M. (2010). Some Notes on Turkish Pronominal Anaphora. Turkish Studies, 5, 535-563.

Meral, H. M. (2013). Binding as an 'A'-phenomenon'?: Some remarks from Turkish. Iberia: International Journal of Theoretical Linguistics, 5, 45-68.

Nicol, J. L., \& Swinney, D. (1989). The role of structure in coreference assignment during sentence comprehension. Journal of Psycholinguistic Research, 18, 5-20.

Özbek, A. \& Kahraman, B. (2016). Interpretations of Turkish reflexive pronouns kendi and kendisi. Mersin Üniversitesi Dil ve Edebiyat Dergisi, 13, 71-94. 
Patterson, C., Trompelt, H., \& Felser, C. (2014). The online application of binding condition B in native and non-native pronoun resolution. Frontiers in Psychology, 5, 147. doi: 10.3389/fpsyg.2014.00147

Pyykkönen, P., \& Järvikivi, J. (2010). Activation and persistence of implicit causality information in spoken language comprehension. Experimental Psychology, 57, 516.

Rayner, K. (1998). Eye Movements in Reading and Information Processing: 20 Years of Research, Psychological Bulletin, 85, 618-660.

Rudnev, P. (2008). Some syntax and semantics of long-distance reflexives in Turkish and elsewhere. Unpublished manuscript. University of Massachusetts, Amherst, MA.

Runner J. T., Sussman, R. S., \& Tanenhaus, M. K. (2006). Assigning referents to reflexives and pronouns in picture noun phrases. Experimental tests of binding theory. Cognitive Science, 30, 1-49.

Schimke, S. \& Colonna, S. (2016). Native and non-native speakers' interpretation of different pronominal forms: Evidence from French and Turkish. Studies in Second Language Acquisition, 38(1), 131-162.

Schneider, W., Eschman, A., \& Zuccolotto, A. (2002a). E-Prime user's guide. Pittsburgh, PA: Psychology Software Tools, Inc.

Schneider, W., Eschman, A., \& Zuccolotto, A. (2002b). E-Prime reference guide. Pittsburgh, PA: Psychology Software Tools, Inc.

Sheldon, A. (1974). The role of parallel function in the acquisition of relative clauses in English. Journal of verbal learning and verbal behavior, 13, 272-281.

Sezer, E. (1980). On reflexivization in Turkish. In I. Ševčenko \& F. E. Sysyn (Eds.), Harvard Ukrainian Studies Eucharisterion: Essays presented to Omeljan Pritsak on his Sixtieth Birthday by his Colleagues and Students, vol.3/4 (pp.748-759). Cambridge, MA: Ukrainian Research Institute, Harvard University.

Sezer, E. (1991). Topics in Turkish Syntax. (Doctoral dissertation). Harvard University.

Stevenson, R., Nelson, A., \& Stenning, K. (1995). The role of parallelism in strategies on pronoun comprehension. Language and Speech, 38, 393-418.

Streb, J., Rösler, F., \& Hennighausen, E. (1999). Event-Related Responses to Pronoun and Proper Name Anaphors in Parallel and Nonparallel Discourse Structures. Brain and Language, 70, 273-286. 
Sturt, P. (2003). The time-course of the application of binding constraints in reference resolution. Journal of Memory and Language, 48, 542-562.

Sturt, P. (2013). Syntactic constraints on referential processing. In R. P. G. van Gompel (Ed.), Sentence Processing (pp. 136-159). East Sussex: Psychology Press.

Turan, Ü. D. (2001). The properties of null objects in Turkish. Sosyal Bilimler Dergisi 2000-2001, 131-144.

Underhill, R. (1976). Turkish Grammar. Cambridge, MA: MIT Press.

Vasishth, S., \& Drenhaus, H. (2011). Locality in German. Dialogue and Discourse, 1, 5982.

Xiang, M., Dillon, B., \& Phillips, C. (2009). Illusory licensing cross dependency types: ERP evidence. Brain and Language, 108, 40-55.

Yakut, A. B. (2015) The logophoric behavior of the strict local anaphor kendi 'self' in Turkish. In A. Joseph \& E. Predolac (Eds.), Proceedings of the 9th Workshop on Altaic Formal Linguistics, MIT Working Papers in Linguistics \#76. Cambridge, MA: MITWPL.

Yang, F., Mo, L., \& Louwerse, M. M. (2012). Effects of local and global context on processing sentences with subject and object relative clauses. Journal of Psycholinguistic Research, 42, 227-237. 